\title{
Decolonizando os Direitos Humanos
}

\author{
Decolonizing human rights
}

\section{Carlos Alberto Motta Cunha*}

Faculdade Jesuíta de Filosofia e Teologia (FAJE), Belo Horizonte, MG, Brasil

\section{Resumo}

"Se hoje dizemos que outro mundo é possível [...] não tenho dúvidas de que é essencial partir sempre dos Direitos Humanos", afirma Franz Hinkelammert. Acolhemos a orientação de Hinkelammert e avançamos para os Direitos da Natureza e Direitos Indígenas como um esforço de decolonizar a própria gramática dos Direitos Humanos. Este é o nosso objetivo. Neste esforço não priorizamos demonstrar os conceitos do pensamento decolonial, mas já incluí-los de forma crítica nas interpelações feitas sobre o resgate do valor da vida dos Direitos Humanos. O nosso percurso consiste em uma breve genealogia dos Direitos Humanos expondo as suas contribuições e os seus limites para, nos momentos seguintes, dar voz de direito à Natureza e aos povos originários, os indígenas, como as maiores vítimas de um sistema-mundo injusto. Ser uma só voz com os oprimidos deveria ser a meta das religiões e suas teologias, em que o conhecimento desemboca em ações concretas de transformação.

Palavras-chave: Decolonialidade. Direitos Humanos. Direitos da Natureza. Direitos Indígenas.

*CAMC: Doutor em Teologia, e-mail: carlosamc04@gmail.com 


\section{Abstract}

"If today we say that another world is possible [...] I have no doubt it is essential to start by looking at Human Rights", says Franz Hinkelammert. Following Hinkelammert's advice, our aim is to move towards the Rights of Nature and Indigenous Rights as an effort to decolonize the very grammar of Human Rights. By doing so, our priority is not to demonstrate the concepts of decolonial thought, but to include them critically into the issues concerned with restoring the value of life as the basis of all Human Rights. Our approach consists of a brief genealogy of Human Rights to highlight their contributions and limits, in order to listen to the rightful voice of Nature and of original and indigenous peoples, the major victims of an unfair world system. Through their knowledge, religions and their theologies should aim to speak the same language as the oppressed, leading to concrete transformative actions.

Keywords: Decoloniality. Human Rights. Rights of Nature. Indigenous Rights.

\section{Introdução}

Não é simples conceituar os "Direitos Humanos". Para Hannah Arendt, os direitos humanos são um construído, uma invenção humana, em constante processo de construção e reconstrução (ARENDT, 2012). A definição dos Direitos Humanos passa pelo crivo de qualquer esforço conceitual: o âmbito socioepistêmico de quem conceitua. O tempo, o lugar e o próprio sujeito dão contornos definitórios sobre algo. É sempre um empenho inconcluso porque os conceitos mudam como modificam-se o mundo e as relações humanas. Assim, "os Direitos Humanos compõem a nossa racionalidade de resistência, na medida em que traduzem processos que abrem e consolidam espaços de luta pela dignidade humana. Realçam, sobretudo, a esperança de um horizonte moral, pautada pela gramática da inclusão, refletindo a plataforma emancipatória de nosso tempo", afirma Flávia Piovesan (PIOVESAN, 2006, p. 6).

Direitos Humanos remetem aos direitos relacionados à garantia de uma vida digna a todas as pessoas. São direitos adquiridos e 
liberdades básicas considerados fundamentais para a dignidade humana. Independente da cor, religião, nacionalidade, gênero e orientação política, todas e todos têm direitos à vida, à liberdade de expressão de opinião, direito à saúde, à educação, ao trabalho e a tantos outros valores universais. De acordo com a Organização das Nações Unidas (ONU), os Direitos Humanos são garantias de proteção das pessoas contra ações ou falta de ações dos governos que possam colocar em risco a dignidade humana.

Será que os Direitos Humanos conseguem abarcar o que propõem? Para Boaventura de Sousa Santos, "a grande maioria da população mundial não é sujeito de direitos humanos. É objeto de discursos de direitos humanos" (SANTOS, 2014, p. 15). Os Direitos Humanos servem ou não à luta dos excluídos? Contribuem para a libertação deles ou reforçam ainda mais políticas de exclusão? Pode o mesmo discurso que legitima a opressão ser usado para a subversão? A linguagem hegemônica da dignidade humana elaborada pelos direitos humanos contempla ou não o sofrimento da humanidade em toda a sua amplidão? Estas são algumas interpelações sobre o empenho dos Direitos Humanos em resgatar, de modo concreto, a humanidade. Não basta ter a consciência dos seus limites; é necessário, sobretudo, propor caminhos decoloniais para "recuperar a 'humanidade' dos Direitos Humanos" (SANTOS, 2014, p. 113).

\section{Os Direitos Humanos e a crítica decolonial}

A busca por direitos e deveres dos indivíduos é uma realidade desde que o ser humano se entende como um sujeito em sociedade. As culturas antigas foram balizadas por documentos que tinham como objetivo a dignidade humana, a justiça e o respeito ao outro. A noção de direitos civis, individuais e coletivos do Ocidente é herdeira dos códigos legais do antigo Oriente. O conjunto de leis dos códigos de Ur-Nammu (2050 a.C), Bilalama (1925 a.C.), Lipite-Istar (1850 a.C.), o código de Hamurabi (1760 a.C.), as leis hetéis (1350 a.C.), o código de aliança dos hebreus (1250 a.C), o Cilindro de Ciro (539 a.C.) e outros estão de algum modo, cada um com 
sua especificidade, no pano de fundo daquilo que hoje conhecemos como Direitos Humanos. Dizer que tais códigos são as primeiras declarações de Direitos Humanos é anacrônico, mas são, sem dúvida, esforços limitados para dar ao indivíduo proteção e um estilo de vida esperado tanto pelo rei quando pela divindade. Havia pouca diferenciação entre o direito religioso, penal e civil. Tanto o direito da cidadania romana, da Roma antiga, quanto o direito natural, teorizado por filósofos cristãos, compõem a genealogia dos direitos à dignidade humana.

Para muitos teóricos do direito, não se pode tratar sobre os Direitos Humanos até a modernidade no Ocidente. Isto porque na antiguidade os direitos e deveres da comunidade estavam correlacionados com o Transcendente, de modo que não havia espaço para direitos individuais fora do contexto comunitário. Os pequenos núcleos sociais, como os familiares e de trabalho, por exemplo, norteiam os direitos da coletividade. O rompimento com esta noção de direito acontece quando surgem noções fundamentais da modernidade:

a ideia de progresso, que faz com que o novo seja considerado superior ao antigo, e a valorização do indivíduo, como lugar da certeza e da verdade, e origem dos valores, em oposição à tradição, isto é, ao saber adquirido, às instituições, à autoridade externa (MARCONDES, 2004, p. 140).

A modernidade não é só um passo de esclarecimento e autonomia do sujeito. Ela oculta processos que reforçam o controle da economia, da natureza e dos recursos naturais, do gênero e da sexualidade, da subjetividade e do conhecimento e, inclusive, dos direitos. A "colonialidade do poder”, sugerida por Aníbal Quijano, faz críticas ao pressuposto fundamental do paradigma moderno ocidental de conhecimento racional e a sua aplicação nas relações de colonização. O conhecimento como produto da relação sujeito-objeto "nega a intersubjetividade e a totalidade como sedes de produção de todo conhecimento" (QUIJANO, 2016, p. 64) por causa do caráter falseador inerente ao sujeito, ser isolado da realidade, e objeto, "coisa" projetada pelo sujeito. Além disso, tal referência modelar "foi parte de uma estrutura de poder que implicava na dominação colonial europeia sobre o resto do mundo. Esse paradigma 
expressou, em um sentido demonstrável, a colonialidade dessa estrutura de poder" (QUIJANO, 2016, p. 65).

A teoria decolonial, consciente dos mecanismos de colonização, provoca atitudes contínuas de transgressão "capazes de incentivar lugares de exterioridade e construções alternativas" (WALSH, 2009, p. 14-15). Decolonizar remete a um sentido estratégico como um instrumento político, epistemológico e social de construção de instituições e relações sociais marcadas pela superação das lógicas opressoras que almejam uma geopolítica mundial perversa e desigual. A crítica decolonial contribui com uma hermenêutica de suspeita em relação à matriz liberal e ocidental que perfaz os Direitos Humanos como direitos individuais que privilegiam os direitos civis e políticos em detrimento do direito coletivo. Santos chama este esforço de "concepção contra-hegemônica dos Direitos Humanos” (SANTOS, 2014, p. 16). Para o sociólogo português, a relação entre direitos e direito tem uma genealogia dupla na modernidade ocidental, marcada pelo pensamento que dicotomizou o mundo entre sociedades metropolitanas e coloniais. A concepção de direitos que daí emergiu vigorou e vigora para atender às demandas das metrópoles e não das colônias. Por parte da colônia ficou, mesmo sem saber, a tarefa de imprimir um caráter contestador e revolucionário sobre o direito e os direitos formulados pela metrópole colonial.

Gramáticas e linguagens de emancipação social dos Direitos Humanos triunfaram como progresso para uns e retrocesso para outros. Os ideais de libertação nacional - socialismo, comunismo, revolução e nacionalismo - constituíram alternativas de dignidade humana e, em determinados tempos e espaços, foram mesmo dominantes (SANTOS, 2014, p. 19).

A partir do século XIX, o discurso dos Direitos Humanos rompeu com a tradição revolucionária, assumindo uma gramática despolitizada de transformação social. O Estado então passou a assumir o monopólio da produção do direito e da administração da justiça dando surgimento ao direito do Estado. Tal mudança reforçou ainda mais a suspeita sobre as reais intenções por trás do discurso a favor da dignidade humana. Santos diz que: 
Gradualmente, o discurso dominante dos direitos humanos passou a ser o da dignidade humana consonante com as políticas liberais, com o desenvolvimento do capitalismo e suas diferentes metamorfoses (liberal, socialdemocrático, dependente, fordista, pós-fordista, fordista periférico, corporativo, estatal, neoliberal etc.) e com o colonialismo igualmente metamorfoseado (neocolonialismo, colonialismo interno, racismo, trabalho análogo ao trabalho escravo, xenofobia, islamofobia, políticas migratórias repressivas etc.) Temos, pois, de ter um mente que o mesmo discurso de direitos humanos significou coisas muito diferentes em diferentes contextos históricos e tanto legitimou práticas revolucionárias como práticas contrarrevolucionárias. Hoje, nem podemos saber com certeza se os direitos humanos do presente são uma herança das revoluções modernas ou das ruínas dessas revoluções. Se têm por detrás de si uma energia revolucionária de emancipação ou uma energia contrarrevolucionária (SANTOS, 2014, p. 21).

A história dos Direitos Humanos é marcada pela ambiguidade de pertença em duas coletividades. Uma é a coletividade da humanidade, pela dignidade inclusiva de todos, e a outra é a coletividade exclusiva dos cidadãos de um determinado Estado.

Ao longo dos últimos duzentos anos, os Direitos Humanos foram sendo incorporados nas constituições e nas práticas jurídico-políticas de muitos países e foram reconceitualizados como direitos de cidadania, diretamente garantidos pelo Estado e aplicados coercitivamente pelos tribunais: direitos cívicos, políticos, sociais, econômicos e culturais (SANTOS, 2014, p. 22).

Há que se questionar sobre a efetividade da proteção ampla dos direitos de cidadania aplicada pelos países que adotaram os Direitos Humanos como paradigma de amparo às coletividades. Por exemplo, a Declaração Universal dos Direitos Humanos das Nações Unidas (1948), ao reconhecer somente dois sujeitos jurídicos - o indivíduo e o Estado - deixa clara a natureza monolítica entre direitos individuais e coletivos. "Os povos são reconhecidos apenas na medida em que se tornam Estados [...] Assim, do ponto de vista das epistemologias do Sul, a Declaração não pode deixar de ser colonialista", afirma Santos (SANTOS, 2014, p. 23). Vale a pena também observar as críticas feitas aos limites da Declaração 
por Jacques Maritain, Teilhard Chardin, Benedetto Croce, Salvador Mandariaga e outros. Harold Laski, por exemplo, diz que:

Se um documento deste tipo se destina a ter uma influência e significado duradouros, é da maior importância recordar que as grandes declarações do passado são uma herança muito especial da civilização ocidental, que estão profundamente imbuídas na tradição da burguesia protestante, que é em si um aspecto saliente da ascensão ao poder da classe média e que, embora a expressão dessas declarações seja universal na forma, as tentativas da sua concretização raramente tiveram qualquer impacto abaixo do nível da classe média [...] Todos os direitos proclamados nos grandes documentos deste gênero são de fato afirmações de uma aspiração, cuja satisfação se encontra limitada pela perspectiva da classe dominante de qualquer comunidade política sobre as relações entre essas proclamações e os interesses que estão determinados em proteger (LASKI, 1948).

O comentário de Laski reforça a suspeita lançada por Karl Marx e Friedrich Engels na Ideologia Alemã de que

os pensamentos dominantes nada mais são do que a expressão ideal das relações materiais dominantes; eles são essas relações materiais dominantes consideradas sob forma de ideias, portanto a expressão das relações que fazem de uma classe a classe dominante; em outras palavras, são as ideias de sua dominação (MARX; ENGELS, 1998, p. 48).

O processo redacional da Declaração dos Direitos Humanos é marcado pela classe dominante incapaz de ver as maiorias colonizadas. Indivíduos, sobretudo do Sul global, não eram iguais perante a lei por estarem sujeitos à dominação. A Declaração tornava invisíveis as exclusões de populações que foram subalternizadas e, portanto, carentes dos direitos em prol da dignidade humana.

Demorou muito tempo para que os Direitos Humanos reconhecessem também classes subalternizadas. Os direitos eram reclamados por povos sujeitos à colonização não europeia e à colonização interna. Em meados dos anos de 1960, as lutas anticoloniais tornaram-se parte da agenda das Nações Unidas. O sexismo, o racismo, o colonialismo e outras formas de dominação começaram a ser vistos como violação dos Direitos Humanos. O direito dos povos indígenas é o exemplo mais 
dramático deste tipo de transgressão da dignidade humana. Os seus direitos começaram efetivamente a ser respeitados a partir da Assembleia Geral de 2007 das Nações Unidas, quando se firmou a Declaração dos Direitos dos Povos Indígenas.

Vimos que os direitos coletivos não fazem parte da genealogia dos Direitos Humanos. "A tensão entre direitos individuais e coletivos resulta da luta histórica dos grupos sociais que, sendo excluídos ou discriminados enquanto grupo, não podem ser adequadamente protegidos pelos direitos humanos individuais", afirma Santos (SANTOS, 2014, p. 26). Os últimos cinquenta anos de reconhecimento de direitos coletivos se deve às lutas das mulheres, dos povos indígenas, afrodescendentes, vítimas do racismo, das violências de gênero, minorias religiosas e ecologistas empenhados no reconhecimento da dignidade do humano e da criação. "Um esforço sempre contestado e em constante risco de reversão" (SANTOS, 2014, p. 26).

\section{Decolonizando os Direitos Humanos}

Decolonizar os Direitos Humanos se tornou uma tarefa urgente e constante. Tendo consciência das limitações da sua gramática em abarcar a coletividade na sua mais profunda miséria, os Direitos Humanos se submetem à tarefa decolonizadora dando origem a uma concepção e a uma prática contra-hegemônica. Santos sugere um caminho para esse empreendimento. Primeiro, é preciso deixar claro que "os direitos são universalmente válidos independentemente do contexto social, político e cultural em que operam e dos diferentes regimes de Direitos Humanos existentes em diferentes regiões do mundo" (SANTOS, 2014, p. 27). Mesmo carentes de um olhar mais profundo e plural sobre o mundo, os Direitos Humanos são a "única gramática e linguagem de oposição disponível para confrontar as 'patologias do poder" (SANTOS, 2014, p. 27). Questioná-los por causa das suas supostas limitações culturais e políticas significa reforçar atos de violência que os Direitos Humanos visam combater. 
Segundo, "se a humanidade é só uma, por que há tantos princípios diferentes sobre a dignidade humana e justiça social, todos pretensamente únicos, e, por vezes, contraditórios entre si?”, pergunta Santos (SANTOS, 2014, p. 28). A constatação do mundo plural de hoje excede em muito uma compreensão ocidental sobre ele. O "uni-verso" em que vivemos sugere uma unidade a partir do diverso, não em um mecanismo rigidamente determinado e único, mas algo aberto e diverso. A antropologia contemporânea afirma que o ser humano é um ser multidimensional e tudo o que acontece a este ser acontece a ele em todas as suas dimensões. O mundo e o humano são realidades complexas demais para um olhar reducionista a partir de um só ponto de vista, a saber, o da compreensão pautada pelo ocidentalismo. Tal parâmetro é um conceito geopolítico capaz de determinar as categorias do pensamento e classificar o resto do mundo. O mundo é maior do que o Ocidente diz sobre ele e, portanto, a compreensão ocidental da "universalidade" dos Direitos Humanos não atende à complexidade do universo.

Terceiro, o problema de reduzir o mundo ao entendimento que o Ocidente tem dele acaba por trivializar as experiências culturais e políticas decisivas em países do sul global. "Este é o caso dos movimentos de resistência contra a opressão, marginalização e exclusão que têm vindo a emergir nas últimas décadas e cujas bases ideológicas pouco ou nada têm a ver com as referências culturais e políticas ocidentais dominantes", constata Santos (SANTOS, 2014, p. 29). São movimentos enraizados em identidades históricas e culturais multisseculares, incluindo muitas vezes a militância religiosa, com formulações estranhas aos Direitos Humanos. Santos menciona três exemplos destes movimentos: indígenas na América Latina; camponeses na África e na Ásia e a insurgência islâmica. Mesmo com significados políticos distintos, estes movimentos "comungam do fato de provirem de referências políticas não ocidentais e de constituírem como resistência ao domínio ocidental" (SANTOS, 2014, p. 29).

Portanto, Santos conclui dizendo que "não se pode aplicar genericamente a mesma receita abstrata dos Direitos Humanos esperando, dessa forma, que a natureza das ideologias alternativas e universos simbólicos sejam reduzidos a especificidades locais sem nenhum impacto no cânone universal dos Direitos Humanos" (SANTOS, 2014, p. 29). É 
necessário libertar a gramática dos Direitos Humanos das amarras do ocidentalismo e criar espaços de abertura capazes de também lutar pela humanização de povos e culturas silenciadas e subalternizadas.

Franz Hinkelammert também aponta para os limites e as ambiguidades na aplicação dos Direitos Humanos. Para ele, o retorno aos Direitos Humanos, hoje, numa perspectiva decolonial, tem sentido não mais em confronto com o Estado totalitário, mas sim contra o sistema de mercado globalizado e neoliberal. A perversidade deste sistema está no fato de negar aos subalternizados e empobrecidos o direito básico de viver com dignidade. Na lógica do mercado, tudo é reduzido à frieza da coisificação para a satisfação dos interesses econômicos. Lutar pelo direito a uma vida digna, em resistência ao sistema de mercado sacralizado, é a única forma de manter a nossa condição humana. Aliás, fundamental para o pensamento de Hinkelammert é o ser humano se revelando enquanto sujeito na medida em que resiste à iniquidade do sistema que o cerca (HINKELAMMERT, 1998).

Para Hinkelammert, "a estratégia de globalização preconiza esquemas de abolição do reconhecimento dos Direitos Humanos” (HINKELAMMERT, 2014, p. 112). Associado a ela, está o crescimento exorbitante das burocracias privadas com a sua lógica de maximização dos lucros resultando na abolição dos Direitos Humanos mais elementares. Os direitos adquiridos pelo Estado social - saúde, educação, habitação, trabalhistas e outros - , foram revogados e entregues a empresas privadas. Assim, todos os direitos são anulados enquanto direitos universais. Só há acesso a eles se você pode pagar. Em nome da privatização e da luta contra as distorções do mercado, promove-se a extinção sistemática dos direitos à vida.

A luta pelos Direitos Humanos é uma batalha social que é preciso assumir, "mas não se pode tratá-la exclusivamente como luta de classes. Seu objetivo precípuo é dominar e controlar as burocracias privadas que estão ameaçando a humanidade. Trata-se, portanto, de uma luta pela sobrevivência da humanidade inteira" (HINKELAMMERT, 2014, p. 118). A burguesia criou seus valores em termos abstratos. A sua teoria econômica é incapaz de perceber que a base de todos os Direitos Humanos são os direitos da vida concreta, direitos econômico-sociais. O discurso 
sobre os Direitos Humanos se torna falseador quando promete paz e não leva em consideração a situação de vida concreta das pessoas. Segundo Hinkelammert, "quem faz todas essas idealizações é precisamente a classe dominante, que não quer falar da última instância econômica da vida humana. No entanto, uma pessoa só consegue viver tendo minimamente assegurados seus direitos à vida, suas possibilidades de viver" (HINKELAMMERT, 2014, p. 114). Parece assim ser impossível reconhecer os Direitos Humanos sem assegurar condições de sobrevivência.

No sistema da globalização neoliberal, o mercado é transformado na única referência de valor superior e tudo mais é tido como inferior. A busca por outro mundo possível com uma sociedade alternativa faz dos Direitos Humanos instrumentos para a intervenção do mercado. Não se pode aceitar a ideia de que propriedade privada é um direito humano. Neste ponto, a Declaração Universal dos Direitos Humanos da ONU continua ambígua porque afirma direitos à pessoa jurídica. O direito "humano" corresponde ao sujeito "como ser corporal integral e que inclui o direito de viver. Expresso em linguagem jurídica, trata-se de direitos de pessoas naturais, diferentemente das pessoas jurídicas. Pessoas jurídicas não têm direitos humanos, porque não são seres humanos; somente pessoas naturais têm esses direitos", conclui Hinkelammert (HINKELAMMERT, 2014, p. 123).

Outra crítica contundente à ambivalência dos Direitos Humanos assinalada por Hinkelammert está no fato da utilização dos Direitos Humanos de forma abstrata para justificar ações assistencialistas, isto é, organizações não governamentais, com o pretexto de "intervenções humanitárias", se utilizam dos Direitos Humanos para legitimarem atos de violência. "Assim transformam-se os Direitos Humanos no imperativo categórico de violá-los” (HINKELAMMERT, 2014, p. 128). A colonização não acabou. No passado, países colonizadores invadiam regiões mais vulneráveis do planeta com o argumento de fazer "evoluir" a humanidade. Assim, saqueavam as riquezas naturais, exploravam a força da mão de obra e destruíam a cultura nativa. Hoje, potências econômicas, sobretudo do Norte global, promovem essa política de colonização, maquiado pelo "bem-estar" dos Direitos Humanos, gerando conflitos. Desse modo, os direitos humanos se transformaram em justificativa para a dominação. 
"Estou convencido de que a inaudita capacidade para a violência, tanto da Europa como dos Estados Unidos nos últimos séculos desde a conquista da América, só é possível porque conseguiram legitimá-la pelo uso dos Direitos Humanos como imperativo categórico para violar os direitos humanos", afirma Hinkelammert (2014, p. 127). Nunca se praticou tanto a violência na história da humanidade como a que vem sendo feita a partir do século XX. "Quase todas as grandes guerras dos séculos XX e XXI são realizadas em nome da humanidade (intervenção humanitária) e dos Direitos Humanos, e a cada investida a destruição é ainda maior que a precedente" (HINKELAMMERT, 2014, p. 127). Infelizmente, em nome dos Direitos Humanos, presenciamos na geopolítica atual crimes contra a humanidade. As vítimas continuam sendo os menos favorecidos de um sistema-mundo injusto e corrupto.

\section{Os Direitos da Natureza}

A crítica decolonial aos Direitos Humanos precisa ser constante no exercício de desmascarar o uso abusivo dos direitos à dignidade humana. Ampliando um pouco mais esta tarefa, constatamos que os direitos à vida dos seres humanos implicam também os direitos da natureza externa ao humano. "Não há ser humano sem natureza em seu entorno, destruir a natureza equivale destruir o ser humano. Nesse sentido, os Direitos da Natureza são simultaneamente Direitos Humanos. É direito humano proteger a natureza para além de qualquer cálculo utilitário”, reforça Hinkelammert (2014, p. 124). O capitalismo, enquanto "economiamundo", segundo o sociólogo norte-americano Immanuel Wallerstein, transformou equivocadamente a Natureza em uma fonte de recursos inesgotáveis. Portanto, não sustentável. A Natureza tem limites biofísicos assim como os humanos. Não ter esta percepção é ignorância em relação à vida.

A humanidade não está fora da Natureza. O ser humano se realiza em comunidade e, como tal, vive com e em função de outros seres humanos como parte integrante da Natureza. Na ecologia profunda, o "uni-verso" (unidade a partir do diverso) é um todo integrado, e não 
como uma coleção de partes dissociadas. Todos os fenômenos estão interligados numa relação de interdependência como uma grande teia da vida. A percepção ecológica profunda "reconhece o fato de que, enquanto indivíduos e sociedades, estamos todos encaixados nos processos cíclicos da natureza (e, em última análise, somos dependentes desses processos)", diz o físico Fritjof Capra (CAPRA, 2006, p. 25). Atentar contra a Natureza é atentar contra o Humano e vice-versa. Qualquer ato de violência repercute em cadeia sobre toda forma de vida.

Propor os Direitos da Natureza não significa negar os avanços da ciência e da tecnologia e o retorno a um mundo idílico. Os progressos feitos não permitem tal retrocesso. A crítica de fundo dos Direitos da Natureza recai sobre o antropocentrismo da ecologia rasa, que centralizada no ser humano e subalterniza a Natureza como objeto a ser explorado, instrumentalizado, a favor da espécie humana. Já numa perspectiva decolonial, a crítica dos Direitos da Natureza permite transparecer como os múltiplos imperialismos colocaram em prática a dominação da Natureza. Conforme Eduardo Galeano:

Desde que a espada e a cruz desembarcaram em terras americanas, a Conquista europeia castigou a adoração da Natureza, que era pecado ou idolatria, com penas de açoite, forca ou fogo. A comunhão entre a Natureza e a gente, costume pagão, foi abolida em nome de Deus e depois em nome da civilização. Em toda América, e no mundo, seguimos sofrendo as consequências desse divórcio obrigatório (GALEANO, 2008).

Dominar e explorar a Natureza, para transformá-la, foram ações contínuas implementadas por grandes corporações preocupadas com o lucro. Ainda hoje, mesmo com maior consciência ecológica, países e empresas persistem na exploração da Natureza visando alimentar a cultura do bem-estar do sistema capitalista neoliberal. Temos uma dívida ecológica. Ela tem a sua origem na espoliação colonial com a extração de recursos naturais das colônias e se "projeta no intercâmbio ecologicamente desigual como na ocupação gratuita do espaço ambiental dos países empobrecidos em decorrência do estilo de vida predatório dos países industrializados" e cresce "na medida em que os países mais ricos superaram em muito seus equilíbrios ambientais nacionais ao transferir 
poluição (resíduos ou emissões) direta e indiretamente a outras regiões sem assumir qualquer ônus por isso", diz Alberto Acosta (ACOSTA, 2016, p. 118-119).

Em 1972, o Clube de Roma deu o alerta sobre o colapso do planeta. $\mathrm{Na}$ ocasião, o relatório encomendado aos cientistas do Instituto de Tecnologia de Massachusetts (MIT), liderados por Dennis e Donella Meadows, sobre a possibilidade do esgotamento dos recursos naturais diante do desenvolvimento industrial, foi taxativo em mostrar os limites da Natureza. O "Relatório Meadows" ou "Os limites do crescimento", como ficaram conhecidas as pesquisas realizadas, previu uma série de problemas decorrentes do crescimento econômico desenfreado. Dificuldades relacionadas à energia, à poluição, ao saneamento, à saúde, à tecnologia, ao crescimento populacional e outras, associadas às condições de vida do ser humano e do planeta foram apontadas em estado de alerta diante da iminência de uma crise ecológica no futuro.

Quase cinquenta anos se passaram desde a elaboração do relatório sobre os limites do crescimento irresponsável e o que vemos hoje são consequências concretas dos desastres sociais e ambientais anunciados. A ONU Meio Ambiente - programa das Nações Unidas, responsável pelas questões relativas aos cuidados e preocupações referentes ao meio ambiente - constantemente denuncia as violações feitas ao planeta e o reflexo disto sobre a vida humana. Por exemplo, a diretora-geral da Unesco, Audrey Azoulay, afirma que "as intervenções humanas - a exploração extensiva dos recursos, os padrões insustentáveis de consumo, a poluição industrial que causa a mudança climática - têm como resultado danos irreparáveis à biodiversidade" 1 . De forma mais concreta, ao cobrar o reconhecimento do direito humano a um meio ambiente saudável e sustentável pelos organismos internacionais, John Knox (relator das Nações Unidas) e Erik Solheim (chefe ambiental da ONU) declaram:

Infelizmente, os vínculos entre direitos humanos e o meio ambiente são frequentemente mais evidentes quando a degradação ambiental causa

1 Cf. "Em dia mundial, ONU celebra 25 anos de convenção para proteger biodiversidade". Disponível em: <https://nacoesunidas.org/em-dia-mundial-onu-celebra-25-anos-de-convencao-para-protegerbiodiversidade/>. Acesso em: 11 jun. 2018. 
doenças, destruição e morte. Mais de 1 milhão de crianças morrem a cada ano como resultado, apenas, da poluição do ar e da água, e as mudanças climáticas e a perda da biodiversidade global ameaçam tanto as gerações presentes, como as futuras².

Relatórios, pesquisas e alertas ambientais não faltam. ONU, Unesco, Greenpeace, World Wide Fund for Nature (WWF) e tantas outras organizações, nacionais e internacionais, empenhadas na denúncia, conservação, investigação e recuperação ambiental dão voz ao grito do planeta que clama por direito à vida. O desafio é criar políticas ambientais em que se reconheça a Natureza como sujeito de direitos. Se buscamos libertá-la da condição de objeto de propriedade dos seres humanos é necessário ter a consciência de que todos os seres têm o mesmo valor ontológico. Eduardo Gudynas lembra a noção de "igualdade biocêntrica" da ecologia profunda em que todas as espécies têm a mesma importância e, portanto, carecem de proteção (GUDYNAS, 2009, p. 34-47). Conceder direitos à Natureza significa incentivar politicamente sua passagem de objeto a sujeito, resgatar o direito à existência dos próprios seres humanos. "Os saberes ancestrais das comunidades indígenas também assumem o mesmo respeito à vida por meio de relações de harmonia com a Pachamama, pois convivem com ela em reciprocidade e respeito", lembra Acosta (ACOSTA, 2016, p. 124).

Há uma distinção importante entre "direitos ambientais" e "Direitos da Natureza". Os Direitos Humanos pressupõem o direito a um ambiente saudável e que não necessariamente implica Direitos da Natureza. "Os direitos ambientais configuram a justiça ambiental, que atende às demandas dos seres humanos — sobretudo, grupos pobres e marginalizados - na defesa da qualidade de suas condições de vida afetadas por desastres ambientais" (ACOSTA, 2016, p. 129). O seu centro gira em torno dos seres humanos e a sua força está em proporcionar a eles um ambiente natural livre da pobreza e da devastação ambiental, que

2 Cf. "Relator e chefe ambiental da ONU cobram reconhecimento do direito humano a um planeta saudável". Disponivel em: <https://nacoesunidas.org/relator-e-chefe-ambiental-da-onu-cobram-reconhecimento-dodireito-humano-a-um-planeta-saudavel/>. Acesso em: 11 jun. 2018. 
provocam impactos negativos na vida do indivíduo. A Natureza tem valor agregado ao bem-estar do sujeito.

Com relação aos Direitos da Natureza, o centro está na própria Natureza. Evidentemente que aqui inclui o ser humano também, mas não numa relação utilitária e sim de cooperação. Na explicação de Acosta, significa que:

A Natureza vale por si mesma, independentemente da utilidade ou dos usos que se lhe atribua. Isto representa uma visão biocêntrica. Estes direitos não defendem uma Natureza intocada, que nos leve, por exemplo, a deixar de cultivar a terra, de pescar ou de criar animais. Estes direitos defendem a manutenção dos sistemas de vida - do conjunto da vida. Sua atenção se volta aos ecossistemas, às coletividades, não aos indivíduos (ACOSTA, 2016, p. 131).

Os Direitos da Natureza foram propostos pela primeira vez em 1972 com a publicação do ensaio Should trees have standing?, de Chistopher Stone. Desde então, debates entre diversos campos do saber se intensificaram no sentido de admitir a Natureza como sujeito de direitos. Hoje, em vários países os Direitos da Natureza embasam legislações em prol da conservação e respeito pelo meio ambiente. Isto só é possível por causa do caso emblemático do Rio Vilacamba, o primeiro processo judicial em que se reconheceu a Natureza como sujeito de direito. Fundamentado na ressignificação e separação da categoria "sujeito de direito", de "pessoa", para a possibilidade de extensão da personalidade jurídica em seu sentido técnico à "Natureza", a decisão judicial no caso Vilacamba, apoiado na norma da Constituição equatoriana de 2008, que garante direitos à Natureza (Pachamama), reconheceu os direitos à proteção e regeneração da Natureza representada judicialmente por dois cidadãos estadunidenses residentes no Equador ${ }^{3}$.

A Assembleia Constituinte do Equador, reunida em Montecristi entre 2007 e 2008, deu passos vanguardistas em prol dos Direitos da Natureza.

3 Para maiores informações sobre o caso Vilacamba e os argumentos sobre os Direitos da Natureza, confira 0 artigo de: GUSSOLI, F. K. A natureza como sujeito de direito na Constituição do Equador: considerações a partir do caso Vilacamba. Disponível em: <http://www.direito.ufpr.br/portal/wp-content/uploads/2014/12/ Artigo-Felipe-Gussoli-classificado-em-1 ${ }^{\circ}$-lugar-.pdf>. Acesso em: 12 jun. 2018. 
Chamados de "mega-direitos" - os Direitos Humanos e os Direitos da Natureza - e, depois, como "meta-direitos" - à água, à soberania alimentar, à biodiversidade, à soberania energética e outros, a Constituição equatoriana dá à Natureza o status de sujeito de direitos e lhe concede o direito de restauração integral em caso de degradação. Importante também foi a incorporação do termo Pachamama como sinônimo de Natureza e o reconhecimento de plurinacionalidade e interculturalidade (ACOSTA, 2016, p. 122). Segundo o artigo 71 da Constituição:

\begin{abstract}
A Natureza ou Pachamama, onde se reproduz e se realiza a vida, tem direito a que se respeite integralmente sua existência e a manutenção e regeneração de seus ciclos vitais, estruturas, funções e processos evolutivos. Toda pessoa, comunidade, povo ou nacionalidade poderá exigir da autoridade pública o cumprimento dos Direitos da Natureza. Para aplicar e interpretar estes direitos, serão observados os princípios estabelecidos na Constituição (ACOSTA, 2016, p. 131).
\end{abstract}

Os Direitos da Natureza são representados por pessoas e comunidades orientadas a proteger os ciclos vitais e os diversos processos evolutivos, não apenas as espécies ameaçadas e as reservas naturais, mas toda forma de vida, assegurando a sobrevivência das espécies e de seus ecossistemas como conjuntos ou redes de vida. Os Direitos da Natureza convidam à pesquisa e ao diálogo com a Natureza, entendendo que o ser humano está imerso nela. "O que se requer é consolidar uma nova forma de inter-relação dos seres humanos com a Natureza, como parte integral da mesma". Isso implica um novo olhar sobre ela "e ao mesmo tempo uma admiração, uma reverência, uma identidade com a Natureza, muito longe de sentimentos de posse e dominação, mas muito próxima da curiosidade e do amor", constata Acosta (ACOSTA, 2011).

O reconhecimento dos Direitos da Natureza não impede o uso dos recursos naturais, mas impõe condições e responsabilidades perante a relação com a Pachamama. A aceitação dos valores intrínsecos dos Direitos da Natureza implica uma crítica decolonial das demandas de crescimento econômico e expansão produtivista a partir da Natureza como objeto a ser explorado. Em vez disso, a proteção de todas as formas de vida, reivindicadas pelo paradigma do biocentrismo, tem uma relação 
de cooperação com a Natureza, privilegiando uma boa qualidade de vida. É uma alternativa ao desenvolvimento, pois está focado nas pessoas e não no crescimento econômico. "Essa abordagem é amplamente sobreposta às discussões atuais sobre alternativas ao desenvolvimento, especialmente com correntes como as da sustentabilidade ou propostas que invocam a ideia do Bem Viver", diz Gudynas (GUDYNAS, 2010, p. 66).

A tendência do antropocentrismo ao biocentrismo em organizar a sociedade e a economia assegurando a integridade dos processos naturais e preservação da biodiversidade parece ser um passo importante na construção de uma civilização pós-capitalista. É cada vez mais urgente uma política internacional em prol da Declaração Universal dos Direitos da Natureza balizada por uma compreensão adequada da Pachamama. Não como sinônimo de "Mãe Terra" - conceito reducionista e machista, uma vez que faz referência somente à fertilidade - , mas "como um todo que vai além da Natureza visível, que vai além dos planetas, que contém a vida, as relações estabelecidas entre os seres e a vida, suas energias, suas necessidades e seus desejos [...]. A Pachamama é um todo e não nos pertence. Nós somos dela", afirmam as feministas comunitaristas (LANG, 2016, p. 116).

Os Direitos Humanos e os Direitos da Natureza se articulam numa espécie de "igualdade biocêntrica". Mesmo sendo analiticamente diferenciáveis, eles se complementam e se transformam em direitos da vida e à vida. Os Direitos da Natureza, imbricados cada vez mais com os Direitos Humanos, convidam a construir democraticamente sociedades sustentáveis como alternativas ao desenvolvimento a partir de cidadanias plurais pensadas também desde o ponto de vista da Natureza (ACOSTA, 2016, p. 140-141).

\section{Os direitos dos povos indígenas}

Infelizmente, ainda não temos uma Declaração Universal dos Direitos da Natureza com o mesmo alcance da Declaração Universal dos Direitos Humanos. Temos a Carta da Terra, como uma tentativa de "constituição" do planeta, promovida no contexto das Nações Unidas 
desde o ano 2000, e a Declaração Universal dos Direitos da Terra, impulsionada pela EnAct International, organização liderada pelo trabalho insistente de Comac Cullinam. Uma declaração com escopo universal que contemple o universo dinâmico e criativo de Pachamama ainda está por ser elaborada.

No entanto, o mesmo não pode ser dito sobre os direitos dos povos indígenas. Mesmo padecendo de limitações conceituais, a declaração das Nações Unidas sobre os Direitos dos Povos Indígenas, reconhecida somente em 2007, busca dar dignidade de vida a um povo que vem sendo espoliado desde sempre. A Assembleia Geral da ONU reconhece isto ao afirmar, no texto introdutório, que:

[...] Preocupada com o fato de os povos indígenas terem sofrido injustiças históricas como resultado, entre outras coisas, da colonização e da subtração de suas terras, territórios e recursos, o que lhes tem impedido de exercer, em especial, seu direito ao desenvolvimento, em conformidade com suas próprias necessidades e interesses,

Reconhecendo a necessidade urgente de respeitar e promover os direitos intrínsecos dos povos indígenas, que derivam de suas estruturas políticas, econômicas e sociais e de suas culturas, de suas tradições espirituais, de sua história e de sua concepção da vida, especialmente os direitos às suas terras, territórios e recursos,

Reconhecendo também a necessidade urgente de respeitar e promover os direitos dos povos indígenas afirmados em tratados, acordos e outros arranjos construtivos com os Estados $[\ldots]^{4}$

Considerada como o instrumento internacional mais abrangente sobre os direitos coletivos dos povos indígenas, incluindo os direitos à autodeterminação, a terras tradicionais e cultura, a Declaração sobre os Direitos dos Povos Indígenas, adotada pela Assembleia Geral da ONU em 13 de setembro de 2007, estabelece diretrizes universais de padrões mínimos de sobrevivência e dignidade dos povos indígenas do mundo. Mais de dez anos se passaram desde a aprovação da declaração e, por mais que progressos tenham sido feitos, os povos indígenas continuam a sofrer

4 Declaração das Nações Unidas sobre os Direitos dos Povos Indígenas. Disponível em: <http://www.un.org/ esa/socdev/unpfii/documents/DRIPS_pt.pdf>. Acesso em: 14 jul. 2018. 
discriminação, marginalização e diversas dificuldades na garantia de seus direitos básicos.

Vimos a relação entre os Direitos Humanos e os Direitos da Natureza no contexto de uma só realidade: a situação planetária. Seres vivos, o humano e a Natureza, com todas as suas formas de vida, compõem um planeta vivo e que qualquer desordem afeta todo o conjunto. A carta encíclica Laudato Si: sobre o cuidado da casa comum, do Papa Francisco, reforça esta ideia quando afirma: "O ambiente humano e o ambiente natural degradam-se em conjunto; e não podemos enfrentar adequadamente a degradação ambiental, se não prestarmos atenção às causas que têm a ver com a degradação humana e social (48)" (FRANCISCO, 2015, p. 38). Pobreza, degradação ecológica, a justiça social, os conflitos étnicos, a paz, a democracia, a ética e a crise espiritual são situações interdependentes que demandam soluções integradas e inclusivas próprias de uma visão holística do planeta. A Carta da Terra é marcada por esta perspectiva. Mark Hathaway e Leonardo Boff, fazendo referência à Carta, dizem:

"Nossos desafios ambientais, econômicos, políticos, sociais e espirituais são interconectados e junto podemos forjar soluções inclusivas". Tais soluções precisam ser inclusivas e englobar todos os diferentes aspectos da atividade humana (pessoal, social e planetário) porque a humanidade chegou a um ponto crítico de sua história e porque as próprias "fundações da segurança global estão ameaçadas” (HATHAWAY; BOFF, 2012, p. 411).

A crise civilizatória, do meio ambiente e da sociedade, afeta principalmente os mais frágeis do planeta. Os índios, os povos originários, como os pobres dos pobres, sofrem as dores da degradação ambiental e social desde a colonização. As marcas da exploração brutal dos colonizadores estão nos seus corpos (mente e coração) e nas suas terras (rios e matas). O sistema-mundo capitalista, globalizante e neoliberal, tem feito a situação dos povos indígenas deteriorar ainda mais e em escala mundial. Sem reconhecimento pelo mundo do consumo, os povos indígenas são abandonados em um nível de vida ignóbil. A marginalização de massas da população somada à exploração de recursos naturais colocam a vida indígena em risco e em situação de integração 
forçada por conta de políticas indigenistas incapazes de valorizar o modo como os índios compreendem a vida.

A violência aos povos indígenas tem marcas de etnocídio e genocídio. "A agressão direta e o massacre impune das comunidades indígenas, como resultado de interesses macroeconômicos ou simplesmente por racismos inveterados, multiplicaram-se nos últimos anos", afirma Eleazar López Hernández (HERNÁNDEZ, 1998). O grito dos índios é um brado de um povo que vem sendo saqueado constantemente. O agronegócio, a especulação imobiliária, as empresas mineradoras e petrolíferas vêm, nas últimas décadas, impondo opressão sobre os povos indígenas. As suas terras são exploradas, os seus membros são mortos ou por causa da incidência de doenças ou por defender a sua região, os seus costumes são negligenciados e assim vão perdendo a sua identidade.

"Os indígenas têm direito, a título coletivo ou individual, ao pleno desfrute de todos os direitos humanos e liberdades fundamentais reconhecidos pela Carta das Nações Unidas, a Declaração Universal dos Direitos Humanos e o direito internacional dos direitos humanos", afirma o artigo 1 da Declaração Universal dos Direitos dos Povos Indígenas. $\mathrm{Na}$ prática, não é isso que vemos. Tomemos como exemplo a realidade dos povos indígenas no Brasil. Em abril de 2018, a Articulação dos Povos Indígenas do Brasil (APIB) redigiu um documento de denúncia e reinvindicação de direitos intitulado "O nosso clamor contra o genocídio dos nossos povos". Nele, cerca de 3.500 lideranças indígenas, representantes dos mais de 305 povos indígenas de todas as regiões do país reclamam os seus direitos e denunciam o massacre e a espoliação dos bens, materiais e culturais, dos povos originários. Segundo o documento:

Completados 30 anos da Constituição Federal de 1988, que consagrou a natureza pluriétnica do Estado brasileiro, os povos indígenas do Brasil vivem o cenário mais grave de ataques aos seus direitos desde a redemocratização do país. Condenamos veementemente a falência da política indigenista, efetivada mediante o desmonte deliberado e a instrumentalização política das instituições e das ações que o Poder Público tem o dever de garantir. O direito originário sobre nossas terras, assegurado como cláusula pétrea pelo Artigo 231 da Constituição, vem sendo sistematicamente violado pelos poderes Executivo, Legislativo e Judiciário, não apenas com 
a completa paralisação das demarcações das terras indígenas, mas também mediante a revisão e a anulação dos processos de reconhecimento dos nossos direitos territoriais ${ }^{5}$.

A situação dos índios, no Brasil, continua caótica. As bancadas parlamentares anti-indígenas, especialmente a ruralista, têm prejudicado o processo de demarcação das terras indígenas. Além disso, a FUNAI, Fundação Nacional do Índio, órgão do governo, demonstra total ignorância com relação à situação dos povos indígenas, acarretando a falta de representatividade. As denúncias feitas pelos índios são graves. A sua voz necessita ser ouvida e os seus direitos, acolhidos. O desmonte do Estado brasileiro provocado pela Emenda Constitucional 95, que congela o orçamento por 20 anos, afeta seriamente programas de apoio aos povos indígenas. As consequências, como descritas no documento:

[...] Impedem as imprescindíveis ações de etnodesenvolvimento, gestão ambiental e proteção das terras indígenas, resultando na intensificação da presença de atividades ilegais e danosas, como garimpo, exploração madeireira, arrendamento, loteamento, comercialização e apossamento de terras já demarcadas por não indígenas; tráfico de conhecimentos tradicionais e outras ameaças [...] A situação de calamidade da saúde indígena, fruto da precariedade do atendimento básico, do desrespeito às particularidades de cada povo indígena, da desvalorização da medicina tradicional, da falta de acesso a medicamentos e ao transporte para a realização de tratamentos, situação agravada pela utilização político-partidária da política e das instâncias responsáveis pela gestão da saúde indígena. [...] Descaso com a educação escolar indígena, manifesta na falta de respeito ao projeto pedagógico de cada povo, no não reconhecimento da categoria de professores indígenas, na falta de apoio à formação continuada desses professores, incluindo as licenciaturas interculturais, e na má qualidade das estruturas das escolas, ou na falta destas nas comunidades, bem como a falta de material didático compatível com as especificidades.

5 Documento final do ATL 2018 - 0 nosso clamor contra o genocídio dos nossos povos. Disponível em: $<$ https:// www.cimi.org.br/2018/04/documento-final-do-atl-2018-o-nosso-clamor-contra-o-genocidio-dosnossos-povos/>. Acesso em: 18 jun. 2018. 
O teor das denúncias não deixa dúvidas: os direitos dos povos indígenas em terras brasileiras estão ameaçados por um governo que não reconhece o seu valor e o seu legado. A política capitalista neoliberal de desenvolvimento a qualquer preço, vislumbrando o aumento do PIB (Produto Interno Bruto) é cruel no trato com os índios, os subalternizados. O projeto de desenvolvimento moderno/colonial continua recrutando "índios, negros e todos nós, mestiços deles, destinados a produzir mercadoria exportável, sem jamais chegar a ser gente com destino próprio" (RIBEIRO, 2015, p. 185). O corpo gerencial das multinacionais assume o papel do senhor de escravos vendido ao mercado financeiro.

Os estudos antropológicos e etnológicos do brasileiro Darcy Ribeiro sempre denunciaram o estado permanente de colonizado do índio no Brasil. "A ignorância e o desprezo pela cultura indígena tornaram-nos incapazes de perceber a importância funcional das instituições tribais, fazendo de sua tarefa mais uma obra de extirpação que de educação", diz ele (RIBEIRO, 2017, p. 44). Mesmo o Serviço de Proteção aos Índios (SPI), em 1910, viabilizado por Cândido Mariano da Silva Rondon, o Marechal Rondon (1865-1958), como movimento de conscientização do reconhecimento das culturas indígenas, e que vai impulsionar a política indigenista brasileira, "jamais chegou a compreender satisfatoriamente a importância funcional dos elementos culturais, sua organização interna e sua interdependência" (RIBEIRO, 2017, p. 187).

O SPI era balizado por princípios que garantiam aos índios o direito à vida: a) Respeito às tribos indígenas como povos que tinham o direito de se realizarem, conservar sua individualidade, professar suas crenças; b) proteção aos índios em seu próprio território, respeitando-se a sua organização tribal; c) proibia o desmembramento da família indígena; d) plena garantia possessória, de caráter coletivo e inalienável, das terras que ocupam, como condição básica para sua tranquilidade e desenvolvimento; d) assegurava a cada índio todos os direitos do cidadão comum, com a atribuição de deveres; e) o direito do índio a viver segundo seus costumes tradicionais, dando a ele a perspectiva de desenvolvimento natural e progressivo. O respeito pela cultura indígena do Marechal Rondon era marcado pela diretiva: "Morrer, se preciso for, matar nunca" (RIBEIRO, 2016, p. 140-170). 
Os princípios indigenistas de Rondon e as reflexões críticas de Ribeiro não têm o acolhimento devido pela política a favor dos índios no Brasil. O território tribal é condição essencial à sobrevivência deles. Retirá-los das suas terras "pode conduzi-los a um colapso, por perda do gosto de viver e desespero diante do destino que lhes é imposto, seguido de desmoralização e extinção", alerta Ribeiro (2017, p. 171). A taxa de mortalidade por suicídio entre indígenas é quase o triplo da média nacional. Enquanto o Brasil registra 5,7 óbitos a cada $100 \mathrm{mil}$ habitantes, o índice é de 15,2 na população indígena. Segundo Lívia Vitenti, da Secretaria Especial de Saúde Indígena, "embora o suicídio seja um fenômeno multifatorial, questões relacionadas à disputa por território têm impacto ainda que indiretamente em determinadas etnias. É uma população que ficou confinada em um território muito pequeno e que vive um problema fundiário constante, o que leva a desavenças, alcoolismo e desestrutura"6.

Os números de suicídios entre os índios de hoje reforçam o impacto negativo dos mecanismos de colonização. Dramática é a experiência narrada por Darcy Ribeiro sobre o suicídio do índio Uirá que, em novembro de 1939, depois de uma série de desenganos, se matou na vila de São Pedro, no Maranhão, lançando-se ao rio Pindaré. O relato de Ribeiro sobre as desventuras de Uirá serve de denúncia permanente desde a colonização do Brasil sobre o desespero dos índios "em consequência da expansão de nossa sociedade e de seus efeitos dissociativos sobre a vida tribal. São casos locais de fenômenos que se verificam em várias partes do mundo onde povos de nível tribal sofreram o impacto da expansão civilizadora da Europa" (RIBEIRO, 2016, p. 13). Não só sofreram, como sofrem. Não só da Europa, mas dos Estados Unidos, de todo o Ocidente e de qualquer lugar do planeta dito "civilizado" que se impõe como cultura hegemônica sobre os povos indígenas.

6 Taxa de suicídio entre indígenas é três vezes maior que a média nacional. Disponível em: <https:// oglobo.globo.com/sociedade/saude/taxa-de-suicidio-entre-indigenas-tres-vezes-maior-que-medianacional-21850401>. Acesso em: 18 jun. 2018. Confira também o relatório da missão ao Brasil da relatora especial da ONU sobre os direitos dos povos indígenas, Victoria Tauli-Corpuz. Disponível em: <http://unsr. vtaulicorpuz.org/site/index.php/es/documentos/country-reports/154-report-brazil-2016>. Acesso em: 18 jun. 2018. 
Somada às denuncias dos trabalhos de Marechal Rondon, Darcy Ribeiro, Claude Lévi-Strauss (os Tristes trópicos, de 1955, por exemplo), A Queda do céu: palavras de um xamã yanomami recolhe o testemunho de vida do índio yanomami Davi Kopenawa ao etnólogo francês Bruce Albert. Kopenawa se tornou um ativista dos direitos indígenas e dos direitos da Natureza, no caso, a Amazônia. A sua presença tem sido uma constante nos últimos anos em alguns espaços sociais e acadêmicos quando se trata da problemática do índio e sua terra. A sua voz representa os "índios e todos os demais povos 'menores' do planeta, as minorias extranacionais que ainda resistem à total dissolução pelo liquidificador modernizante do Ocidente", afirma Eduardo Viveiros de Castro (CASTRO, 2015, p. 15).

Castro, ainda no prefácio do livro $A$ Queda do céu, interpela o leitor sobre as provocações feitas pelo relato de Kopenawa. Nele aprendemos algo de essencial sobre o estatuto ontológico e antropológico do "homem branco".

Somos representantes quaisquer desse povo bárbaro e exótico proveniente de além-mar, que espanta por sua absurda incapacidade de compreender a floresta, de perceber que "a máquina do mundo" é um ser vivo composto de incontáveis seres vivos, um superorganismo constantemente renovado pela atividade vigilante de seus guardiões invisíveis, os xapiri, imagens "espirituais" do mundo que são a razão suficiente e a causa eficiente daquilo que chamamos Natureza - em yanomami, hutukara —, na qual os humanos estamos imersos por natureza (CASTRO, 2015, p. 13).

A voz indígena é uma voz de gente excluída que confronta os valores da modernidade e revela a ganância e a perversidade da colonização atrelada a ela. Os Direitos indígenas se inscrevem nos Direitos Humanos e nos Direitos da Natureza como um alerta para todo o planeta. Ouvir a voz dos nossos antepassados significa reavaliar o tipo de vida que levamos e que mundo deixaremos para as gerações futuras. É preciso acolher a sabedoria indígena e deixar que ela decolonize o nosso imaginário de modo libertador. Nas palavras de Davi Kopenawa:

Eu não aprendi a pensar as coisas da floresta fixando os olhos em peles de papel. Vi-as, de verdade, bebendo o sopro de vida de meus antigos com o 
pó de yãkoana que me deram. Foi desse modo que me transmitiram também o sopro dos espíritos que agora multiplicam minhas palavras e estendem meu pensamento em todas as direções. Não sou um ancião e ainda sei pouco. Entretanto, para que minhas palavras sejam ouvidas longe da floresta, fiz com que fossem desenhadas na língua dos brancos. Talvez assim eles afinal as entendam, e depois deles seus filhos, e mais tarde ainda, os filhos de seus filhos. Desse modo, suas ideias a nosso respeito deixarão de ser tão sombrias e distorcidas e talvez até percam a vontade de nos destruir. Se isso ocorrer, os nossos não mais morrerão em silêncio, ignorados por todos, como jabutis escondidos no chão da floresta (KOPENAWA; ALBERT, 2015, p. 76).

\section{Considerações finais}

Movimentos de empoderamento em favor daqueles que são explorados e subalternizados, tanto do Humano quanto da Natureza, assinalam para práticas sociais e ecológicas alternativas da espécie. Ao mesmo tempo, toda forma de colonização é criticada pela prática decolonial do poder como ponto de partida para orientação de novas alternativas de desenvolvimento planetário. Somos provocados hoje a repensar o nosso estilo de vida. O nosso mundo precisa ser recriado a partir do âmbito comunitário. "É necessário construir relações de produção, de intercâmbio e de cooperação que propiciem suficiência - mais que apenas eficiência - sustentada na solidariedade", afirma Acosta. ${ }^{7}$ Como surge de raízes comunitárias não capitalistas, a cosmovisão dos povos originários rompe com a lógica antropocêntrica da modernidade e questiona as motivações de ações colonizadoras.

A decolonização dos Direitos Humanos e o avanço crítico para os Direitos da Natureza e os Direitos Indígenas interpelam as religiões e suas teologias a uma lógica capaz de transformar a realidade. Mais do que refletir e interpretar a vida, é preciso mudá-la. A teologia das religiões tem uma atitude crítica, iluminada pelas demandas do contexto e empenhada na construção de um mundo melhor. Primeiro o serviço em prol da

7 ACOSTA, 2016, p. 27. 
existência, a caridade, o amor em ação e, depois, a elaboração teológica teórica. O discurso teológico e/ou religioso é um discurso a serviço de um processo de transformação real. Segundo Ignacio Ellacuría:

o caráter práxico essencial da vida humana se apresenta eticamente como a necessidade de cuidar para que a realidade seja como deve ser, que se faça com a realidade o que se deve fazer; a realidade é sempre dinâmica, é um realizar-se; o ser do homem é um fazer-se (ELLACURÍA, 2009, p. 261).

\section{Referências}

ACOSTA, A. O Bem viver: uma oportunidade para imaginar outros mundos. Rio de Janeiro: Autonomia Literária; Ed. Elefante, 2016.

ACOSTA, A. Por uma Declaração Universal dos Direitos da Natureza: reflexões para a ação. Unisinos Notícias, 25 mar. 2011. Disponível em: <http://www. ihu.unisinos.br/noticias/41738-por-uma-declaracao-universal-dos-direitos-da-natureza-reflexoes-para-a-acao >. Acesso em: 12 jun. 2018.

ARENDT, H. As Origens do Totalitarismo. São Paulo: Companhia das letras, 2012.

CAPRA, F. A teia da vida: uma nova compreensão científica dos sistemas vivos. São Paulo: Cultrix, 2006.

CASTRO, E. V. de. O recato da mata. In: KOPENAWA, D.; ALBERT, B. A queda do céu: palavras de um xamã yanomami. São Paulo: Companhia das letras, 2015.

ELLACURÍA, I. Cursos universitarios. El Salvador: UCA Editores, 2009.

GALEANO, E. A natureza não é muda. Carta maior, 23 abr. 2008. Disponível em: <https://www.cartamaior.com.br/?/Editoria/Meio-Ambiente/A-natureza-naoe-muda/3/14112>. Acesso em: 11 jun. 2018.

GUDYNAS, E. La ecología política del giro biocéntrico en la nueva Constitución de Ecuador. Revista de Estudios Sociales, Bogotá, n. 32, p. 34-47, abr. 2009.

GUDYNAS, E. La senda biocéntrica: valores intrínsecos, derechos de la naturaleza y justicia ecológica. Tabula Rasa, Bogotá, n. 13, jul./dic. 2010. 
HATHAWAY, M.; BOFF, L. O tao da libertação: explorando a ecologia da transformação. Petrópolis: Vozes, 2012.

HERNÁNDEZ, E. L. Los indios ante el Tercer Milenio. Portal Koinonía, ago. 1998. Disponível em: 〈http://servicioskoinonia.org/relat/194.htm>. Acesso em: 15 jun. 2018.

HINKELAMMERT, F. El grito del sujeto: del teatro-mundo del evangelio de Juan al perro-mundo de la globalización. San José, Costa Rica: Editorial DEI, 1998. HINKELAMMERT, F. Mercado versus direitos humanos. São Paulo: Paulus, 2014. KOPENAWA, D.; ALBERT, B. A queda do céu: palavras de um xamã yanomami. São Paulo: Companhia das letras, 2015.

LANG, M. et al. Pensar a partir do feminismo: críticas e alternativas ao desenvolvimento. In: DILGER, G.; LANG, M.; PEREIRA FILHO, J. Descolonizar o imaginário: debates sobre o pós-extrativismo e alternativas ao desenvolvimento. São Paulo: Fundação Rosa Luxemburgo, 2016.

LASKI, H. Toward a Declaration of Human Rights. In: Unesco Human Rights: comments and interpretations. Paris, 1948. Disponível em: <http://unesdoc.unesco. org/images/0015/001550/155042eb.pdf >. Acesso em: 5 jun. 2018.

MARCONDES, D. Iniciação à história da filosofia: dos pré-socráticos a Wittgenstein. 8. ed. Rio de Janeiro: Jorge Zahar, 2004.

MARX, K.; ENGELS, F. E. A ideologia alemã. São Paulo: Martins Fontes, 1998.

FRANCISCO. Laudato Si: sobre o cuidado da casa comum. São Paulo: Paulinas, 2015.

PIOVESAN, F. Direito Constitucional. Módulo V: direitos humanos e o direito constitucional internacional. 2006. p. 6. Disponível em: <https://www2.trf4.jus. $\mathrm{br} / \mathrm{trf} 4 /$ upload/arquivos/emagis_atividades/ccp5_flavia_piovesan.pdf $\rangle$. Acesso em: 28 maio 2018.

QUIJANO, A. Colonialidad y modernidad-racionalidad. In: PALERMO, Z.; QUINTERO, P. (Coord.). Aníbal Quijano: textos de fundación. Buenos Aires: Editorial: Ediciones del Signo, 2016. 
RIBEIRO, D. O povo brasileiro: a formação e o sentido do Brasil. 3. ed. São Paulo: Global, 2015.

RIBEIRO, D. Os índios e a civilização: a integração das populações indígenas no Brasil moderno. 7. ed. São Paulo: Global, 2017.

RIBEIRO, D. Uirá sai à procura de Deus. 4. ed. São Paulo: Global, 2016. p. 140-170.

SANTOS, B. de S. Se Deus fosse um ativista dos direitos humanos. 2. ed. São Paulo: Cortez, 2014.

WALSH, C. Interculturalidad, Estado, Sociedad: Luchas (de)coloniales de nuestra época. Quito: Universidad Andina Simón Bolivar; Ediciones Abya-Yala, 2009. p. 14-15. Disponível em: <http://www.flacsoandes.edu.ec/interculturalidad/wp-content/uploads/2012/01/Interculturalidad-estado-y-sociedad.pdf $>$. Acesso em: 30 abr. 2018.

Recebido: 10/02/2019

Received: 02/10/2019

Aprovado: 24/04/2019

Approved: 04/24/2019 